\title{
Preferences of SAUdi USers on Arabic WEBSITE USABILITY
}

\author{
Lulwa Alyahyan ${ }^{1}$, Hamza Aldabbas ${ }^{2}$ and Khalid Alnafjan ${ }^{3}$ \\ ${ }^{1}$ King Abdulaziz City for Science and Technology, Riyadh, KSA \\ ${ }^{2}$ Prince Abdullah bin Ghazi Faculty of Information and Technology, Al-Balqa' Applied \\ University, Salt- Jordan \\ ${ }^{3}$ Software Engineering Department, King Saud University, Riyadh, KSA
}

\begin{abstract}
The aim of this paper is to conduct a study on the Saudi culture to extract Saudi users' preferences on Arabic website usability. Its purpose is to determine the most important issues that should be considered when designing for the Saudi culture. The data collection instrument consist of an online questionnaire for Saudi Internet users'. The main outcome of this study is that Saudi users agree on the importance of website usability issues such as adherence to local language, culture, and religious beliefs, in addition to consistency in navigation scheme, messages, and text format. The results of this study highlight the need to consider the cultural preferences of the target audience for successful local websites or applications.
\end{abstract}

\section{KEYWORDS}

Usability, user interface, Saudi Arabia, design, guidelines

\section{INTRODUCTION}

The Internet enables users to communicate, access information, and perform different tasks through websites. Web designers need to design user interfaces that are usable and well accepted in a targeted culture. Culture becomes a critical issue in website design [1]. More and more localized versions of websites or applications have been developed over the last few years in order to address target national or cultural user groups. People from different cultures understand and interpret several issues (such as colors, graphics and signs) in different ways. For example, the same color can have different meanings to people from different cultures, causing them to react differently. Barber and Badre [2] gave an example of the red color: for the Chinese, it means happiness; for the Japanese, it means anger or danger; for the Egyptians, it means death; and for the Americans, it means danger or stop. Therefore, companies that aim to develop local websites should consider local user preferences, likes, and dislikes to provide a preferable user interface and eliminate any culturally offensive material. This paper contributes to the study of this complex by conducting a survey to extract and analyze the preferences of Saudi users on Arabic website usability. The results of the survey support the creation of cultural usability guidelines for the Saudi audience. 
Issues of culture and usability are no longer separate in web design. In order to meet users' cultural expectations, combining usability knowledge and cultural insights is needed. Brejcha et al. [3] indicated that usability knowledge needs to consider cultural insights, which will have a return of lower costs and better acceptance. Previous studies by $[4,5]$ have indicated the impact of culture on designing usable websites. According to Nantel and Glaser [6], a "culturally adapted website results in greater ease of navigation and a more positive attitude towards the site." Consideration of cultural issues in the design of a web-based system can improve the usability of such system [4]. The "one size fits all" formula no longer holds in web interface design. The cultural background of users need to be considered in web design to enable them to experience success and satisfaction [7]. Numerous studies state that many websites fail because of the web designer's ignorance or insufficient understanding of the target users' local culture.

Cultural preferences of interface design elements influence the acceptance of a user interface [8]. The users' preference survey by [9] highlighted the importance of understanding the cultural preferences of the target audience when designing websites. Elbaz et al. [8] created usability guidelines to suit the requirements of Internet users from an Arabic background (culture). The guidelines were extracted based on the user acceptance test (UAT) reports of projects in Arab countries. There are many research studies in the field of cross-cultural comparison of user interface (UI) elements, such as [1], [9], [10], [11],[3], and [2]. However, limited work has been done in defining a usable set of UI design guidelines for a target culture.

With the recent emergence of companies marketing products locally, the increasing interest in culture by designers and developers is evidenced by the fact that culture and its impact on usability is an important factor in the user interface development process that directly influences local users who use websites or applications. As a result, it is important that the preferred user interface design elements such as navigational structures, colors, symbols, and icons are considered before local websites or applications are marketed locally.

This paper is divided into six sections. Section 1 provides the introduction, section 2 describes the study method, section 3 describes the study results, section 4 discusses the results, section 5 describes cultural usability guidelines, and section 6 describes conclusions.

\section{STUDY METHOD}

Questionnaire is used in the study as a data collection method. The questionnaire is for Saudi Internet users, and it is divided into six main sections (target audience characteristics, general website/web application issues, images/graphics, navigation and scrolling, alignment and placement of elements, and colors). The study of Internet users is conducted to students at the university, IT professionals, and academics in KSA. The questionnaire was distributed in King Saud University (KSU) and King Abdulaziz City for Science and Technology (KACST). The sample consists of 90 individuals from KSU and KACST.

\section{Case Study Results}

In this section, the authors outline the results obtained from the survey according to the six sections listed above: 


\subsection{Target Audience Characteristics}

Table 1 summarizes the descriptive statistics of the respondents. It can be seen that the majority of the respondents are 18-28 years of age and there is an equal number of males and females. In terms of educational of level, majority of them are in the secondary school or bachelor's degree level. The respondents are asked to evaluate their web surfing skills, and the results clearly show that almost half of them have advanced surfing skills, whereas others have intermediate to poor surfing skills.

Table 1: Sample's descriptive statistics

\begin{tabular}{|l|l|l|l|}
\hline \multicolumn{2}{|l|}{ Item } & Freq. & \% \\
\hline \multirow{4}{*}{ Gender } & Male & 45 & $50.00 \%$ \\
\cline { 2 - 4 } & Female & 45 & $50.00 \%$ \\
\hline \multirow{5}{*}{ Education } & $18-28$ & 74 & $82.2 \%$ \\
\cline { 2 - 4 } & $29-39$ & 13 & $14.4 \%$ \\
\cline { 2 - 4 } & $40-50$ & 3 & $3.3 \%$ \\
\cline { 2 - 4 } & 51 or older & 0 & $0 \%$ \\
\cline { 2 - 4 } & Secondary education & 38 & $42.2 \%$ \\
\cline { 2 - 4 } & $\begin{array}{l}\text { Diploma or associate } \\
\text { degree }\end{array}$ & 2 & $2.2 \%$ \\
\cline { 2 - 4 } & Bachelor's degree & 32 & $35.6 \%$ \\
\cline { 2 - 4 } & Master's degree & 11 & $12.2 \%$ \\
\cline { 2 - 4 } & PhD degree & 7 & $7.8 \%$ \\
\hline \multirow{5}{*}{ Surfing Skills } & Poor & 11 & $12.2 \%$ \\
\cline { 2 - 4 } & Intermediate & 31 & $34.4 \%$ \\
\cline { 2 - 4 } & Advanced & 48 & $53.3 \%$ \\
\hline
\end{tabular}

\subsection{General Website/Web Application Issues}

Regarding general website/web application issues, the results of the statistical analysis show that designers, when designing for the Saudi culture, need to consider the following features as the majority of the respondents thought that considering them was important:

- User's own (native) language (82.22\%)

- Saudi culture (52.22\%) and Islamic beliefs (67.78\%)

- Website/web application authenticity (53.33\%)

- Fast download of a website/web application (83.33\%)

- Strong security and privacy $(78.89 \%)$

- Website/web application accessibility for disabled users (53.33\%)

- Customer services such as online chat and e-mail (51.11\%)

- Search service for information on the website/web application (68.89\%)

- Consistency of error, confirmation, and prompt messages displayed throughout the website/web application $(61.11 \%)$

- Consistency of font type, size, and style (57.78\%)

- Ability to undo or reverse actions $(68.89 \%)$

- Ability to prevent errors from occurring (75.56\%)

- Ability to recognize, diagnose, and recover from errors (76.67\%) 


\subsection{Images/Graphics}

The results of the statistical analysis show that most of the respondents agreed that images/graphics should adhere to the Saudi culture and Islamic beliefs (68.89\%). Furthermore, the respondents agreed that animation could help convey information better $(51.11 \%)$. They disliked advertisement images (58.89\%) and images/graphics that flash or move around (46.67\%).

\subsection{Navigation and Scrolling}

The majority of the respondents $(60.00 \%)$ preferred "vertical scrolling," and about $50 \%$ disliked "horizontal scrolling." They were neutral regarding the position of the vertical scrolling bar on the left-hand side $(53.33 \%)$, although more respondents preferred it (32.22\%). Furthermore, 54.44\% of the respondents preferred the navigation bar to be positioned on the top and right of the page. On the other hand, about $49 \%$ disliked the navigation bar to be positioned on the top and left of the page. This may be an expected response due to the fact that the Arabic language is written from right to left. Additionally, over 55\% agreed on the following navigation features presented in the questionnaire:

- Navigation bar on every page $(55.56 \%)$

- "Back" and "Next" buttons $(81.11 \%)$

- "Home" button on every page (or equivalent) $(85.56 \%)$

- Links leading to the correct page $(91.11 \%)$

- Meaningful links text that clearly identifies the destination $(64.44 \%)$

- Consistent navigation scheme or link styles throughout the site (57.78\%)

- Current page location easily recognizable within the site (78.89\%).

\subsection{Alignment and Placement of Elements}

Regarding the alignment and placement of elements, 50\% of the respondents agreed on the position of the content in the center of the page. Most of them preferred "right alignment" (54.44\%) and disliked "left alignment." Also, most of them agreed on the position of the important content in the center of the page (72.22\%) or in the top-right part of the page (52.22\%), and $42.22 \%$ disagreed with the statement that "important content must be on the top-left part of the page." Furthermore, most of them agreed on the position of the logo on the top center (56.67\%) or top-right part of the page (42.22\%), and $46.67 \%$ disagreed with the statement that the "logo must be on the top-left part of the page." These results may be expected because of the direction of the written language.

\subsection{Colors}

The use of color in interface design may have a greater impact on the user's satisfaction and expectations [12]. Regarding website/web application colors, the majority of the respondents preferred cold colors (e.g., blue and green) (85.56\%) and preferred dark text colors $(77.78 \%$ ), particularly black $(70.00 \%)$. They preferred a white page background $(74.44 \%)$. Furthermore, about $(30 \%)$ of them preferred blue or gray for the menu background. 


\section{DISSCUION}

The study highlights users' preferences for the Saudi culture. As can be seen from the results in the previous section, cultural background has a significant influence on user interface acceptance [13]. Therefore, the findings from the survey enable the researcher to construct "cultural usability guidelines" for Saudi Arabia. The guidelines deal with culture-related usability issues of the user interface. They are created to form desirable features when designing for Saudis. They are expected to be used as a reference for web designers or developers in Saudi Arabia.

Regarding general website/web application issues, the Saudi respondents emphasized that when designing for the Saudi culture, the Saudi culture and Islamic beliefs need to be considered. However, other cultures such as the British culture do not consider them important [14]. Furthermore, the Saudi respondents emphasized the importance of the user's own language, website/web application authenticity, accessibility, strong security and privacy, fast download, customer services, and search service. They considered consistency of messages and text format to be important issues.

Regarding the images/graphics on a website, the Saudi respondents were more attuned to culture and religious beliefs in their answers and emphasized the importance of those images to adhere to the Saudi culture and Islamic beliefs where other cultures such as the British culture have a fairly relaxed attitude to anything they see on the site [14].

Regarding navigation, alignment, and placement of elements, the Saudi respondents preferred right alignment and positioning important content in the center or top right of the web page and the navigation bar on the top and possibly on the right of the page. This may be due to the direction of the Arabic language. However, other cultures that use the English language such as the British culture prefer left alignment and emphasize that the center or top left of the web page is likely to catch users' attention [14]. Furthermore, the Saudi respondents preferred the logo to be in the top center or top right of the web page.

Regarding website/web application colors, the Saudi respondents preferred cold colors (e.g., blue and green) and dark text colors. Furthermore, they preferred a white background. This concurs with a study by Mohammadi et al. [15], where the result showed that white color, which symbolizes purity and peace in the Arabic culture, has been used prominently as background color for most websites related to the Arabic culture.

The result obtained from the questionnaire highlighted the need to consider the users' cultural background and preferences to ensure user acceptance and satisfaction.

\section{Cultural Usability Guidelines}

From the survey results, all the UI elements, features, and issues related to the Saudi culture and preferences were combined to form the desirable features when designing for Saudis. Table 2 summarizes these features, which designers should consider carefully. 
Table 2: Cultural usability guidelines for Saudi Arabia

\begin{tabular}{|c|c|}
\hline No & Guideline \\
\hline & General website/web application issues \\
\hline 1 & Adherence to the users' Islamic belief systems \\
\hline 2 & Adherence to the native Arabic language \\
\hline 3 & Adherence to the Saudi culture (basic ethical and moral values) \\
\hline 5 & Authenticity (author, publication date, institute) for articles \\
\hline 6 & $\begin{array}{l}\text { Providing fast download time for the whole website/web application as well as } \\
\text { per individual web page }\end{array}$ \\
\hline 7 & Providing a strong security and privacy assurance \\
\hline 8 & Providing accessibility for people with special needs \\
\hline 9 & Providing customer services such as e-mail and online chat \\
\hline 10 & Providing search service for information on the site \\
\hline 11 & $\begin{array}{l}\text { Ensuring consistency of error, confirmation, and prompt messages displayed } \\
\text { throughout the website/web application }\end{array}$ \\
\hline 12 & Ensuring consistency of font type, size, and style \\
\hline 13 & Ability to undo or reverse actions \\
\hline 14 & Ability to prevent errors from occurring \\
\hline \multirow[t]{2}{*}{15} & Ability to recognize, diagnose, and recover from errors \\
\hline & Graphics \\
\hline 16 & Images/graphics adhering to the Saudi culture and Islamic beliefs \\
\hline 17 & Some use of animation to help convey information \\
\hline 18 & Avoidance of images/graphics that flash or move around \\
\hline \multirow[t]{2}{*}{19} & Avoidance of advertisement images \\
\hline & Navigation and scrolling \\
\hline 20 & Vertical scrolling bar positioned on the left of the page \\
\hline 21 & Avoiding horizontal scrolling to display page contents \\
\hline 22 & Vertical scrolling to display page contents \\
\hline 23 & Navigation bar position on top and possibly on the right-hand side of the page \\
\hline 24 & Navigation bar on every page \\
\hline 25 & "Back," "Next," and "Home" buttons (or equivalent) \\
\hline 26 & "Home" button on every page (or equivalent) \\
\hline 27 & Links leading to the correct page \\
\hline 28 & Meaningful links text that clearly identifies the destination \\
\hline 29 & Consistent navigation scheme throughout the website/web application \\
\hline \multirow[t]{2}{*}{30} & Current page location easily recognizable within the site \\
\hline & Placement and alignment of elements \\
\hline 31 & Content centered on a page \\
\hline 32 & Text right aligned \\
\hline 33 & Important content in the center or top right-hand corner of a web page \\
\hline \multirow[t]{2}{*}{34} & Logo on the top center or top right of the web page \\
\hline & Colors \\
\hline 43 & Cold colors such as blue and green more attractive for a website \\
\hline 44 & Dark text colors \\
\hline 45 & White background and black text \\
\hline
\end{tabular}




\section{Conclusions}

To ensure that the final design is locally usable, you need to investigate the preferences of users within your target culture and take them into account during the design phase. As the development of local websites/applications increases, the challenge of enabling more people from a target culture to use the content of websites and applications effectively will increasingly depend on the understanding of cultural preferences.

In designing websites for a Saudi audience, the researchers concluded that adherence to the local language, culture, and religious beliefs is important. Consistency was also highly rated in relation to navigation, messages, and text format. The findings of the study helped build cultural usability guidelines for the Saudi audience. It drew attention to the importance of fully understanding the culture of the target audience for a website design to be successful. By attending to the needs of local users through the development of usable local applications and websites, companies will achieve greater success and increased profitability.

\section{REFERENCES}

[1] H. S. Al-Khalifa and R. A. Garcia, "Website Design Based on Cultures: An Investigation of Saudis, Filipinos, and Indians Government Websites' Attributes," in Design, User Experience, and Usability. User Experience Design for Diverse Interaction Platforms and Environments, ed: Springer, 2014, pp. 15-27.

[2] W. Barber and A. Badre, "Culturability: The merging of culture and usability," in Proceedings of the 4th Conference on Human Factors and the Web, 1998, pp. 1-10.

[3] J. Brejcha, G. H. Yin, H. Li, and Z. Liu, "A Cross-Cultural Comparison of UI Components Preference between Chinese and Czech Users," in Cross-Cultural Design. Methods, Practice, and Case Studies, ed: Springer, 2013, pp. 357-365.

[4] A. O. Daniel, A. Oludele, R. Baguma, and T. Weide, "Cultural issues and their relevance in designing usable websites," Computing, pp. 20-29, 2011.

[5] C. Lodge, "The impact of culture on usability: designing usable products for the international user," in Usability and Internationalization. HCI and Culture, ed: Springer, 2007, pp. 365-368.

[6] J. Nantel and E. Glaser, "The impact of language and culture on perceived website usability," Journal of Engineering and Technology Management, vol. 25, pp. 112-122, 2008.

[7] B. Shneiderman, "Universal usability: Pushing human-computer interaction research to empower every citizen," MEDIA ACCESS, p. 255, 1999.

[8] P. Elbaz, G. H. Galal-Edeen, and M. Gheith, "The Influence of Culture on Systems Usability," International Journal of Software Engineering, IJSE vol. 4, pp. 93-114, 2011.

[9] A. H. Al-Badi and P. J. Mayhew, "Website design Considerations: Understanding Users' Needs," in UKAIS 2004 Conference, 2004.

[10] A. Smith, L. Dunckley, T. French, S. Minocha, and Y. Chang, "A process model for developing usable cross-cultural websites," Interacting with computers, vol. 16, pp. 63-91, 2004.

[11] A. Marcus and E. W. Gould, "Crosscurrents: cultural dimensions and global Web user-interface design," interactions, vol. 7, pp. 32-46, 2000.

[12] M. C. A. Tong and K. Robertson, "Political and cultural representation in Malaysian websites," International Journal of Design, vol. 2, pp. 67-79, 2008.

[13] A. H. Al-Badi and P. J. Mayhew, "A framework for designing usable localised business websites," Communications of the IBIMA, vol. 2010, pp. 1-24, 2010.

[14] A. H. Al-Badi, "A framework for designing usable localised websites," University of East Anglia, 2005.

[15] M. A. Khanum, S. Fatima, and M. A. Chaurasia, "Arabic Interface Analysis Based on Cultural Markers," arXiv preprint arXiv:1203.3660, 2012. 
International Journal of Web \& Semantic Technology (IJWesT) Vol.7, No.3/4, October 2016

\section{AUTHORS}

Lulwah Alyahyan recived her Bsc in Computer Applications from King Saud University (Riyadh, KSA) and Msc in Software Engineering from the same university. Since 2009, she has been a research faculty member of the Computer Research Institute at King Abdulaziz City for Science and Technoogy (KACST), Riyadh, KSA, she has done research in several areas including natural language processing and web usability.

Hamza Aldabbas is an Assistant Professor at Al-Balqa'a Applied University /Prince Abdullah Bin Ghazi Faculty of Science and Information Technology-Jordan, Previously a lecturer at De Montfort University/UK, with responsibility for teaching and project supervision (2010-to 2012). Received his PhD Degree in Computer Science and Software Engineering, De Montfort University, Leicester-United Kingdom (2009-2012).Previously M.Sc, Computer Science (2009) and B.Sc Computer Information Systems (2006) from Al-Balqa'a Applied University, Al-Salt, Hashemite Kingdom of Jordan. His research interests are in Ad hoc Networks, Grid computing, Context-aware Systems and E-commerce.

Dr khalid alnafjan is an associate professor at the software engineering department, college of computer and information sciences at king Saud univeristy. His research interests lie in software usability, software process improvement, and C4i systems. 